\title{
lodoform Vs Calcium Hydroxide/Zinc Oxide based pastes: 12-month findings of a Randomized Controlled Trial
}

\section{Daniele Vieira CASSOL ${ }^{(a)}$ Maysa Lannes DUARTE(a) Andrea Vaz Braga PINTOR(a) Roberta BARCELOS(b) Laura Guimarães PRIMO(a)}

(a) Universidade Federal do Rio de Janeiro UFRJ, School of Dentistry, Department of Pediatric Dentistry and Orthodontics, Rio de Janeiro, RJ, Brazil.

(b) Universidade Federal Fluminense, Health Institute of Nova Friburgo, Nova Friburgo, RJ, Brazil
Declaration of Interests: The authors certify that they have no commercial or associative interest that represents a conflict of interest in connection with the manuscript.

\section{Corresponding Author:}

Laura Guimarães Primo

E-mail: Iprimo@pobox.com

htps://doi.org/10.1590/1807-3107bor-2019.vol33.0002

Submitted: July 11, 2018

Accepted for publication: November 05, 2018

Last revision: November 26, 2018

\begin{abstract}
This study evaluated clinical and radiographic twelve-month outcomes of root canal treatments (CT) with smear layer removal, performed in primary teeth, using two different root canal filling materials. Pulpectomy was performed on 27 primary teeth with necrosis or irreversible pulpitis, caused by dental caries or trauma, in 23 children (2-7 years old). A single trained operator performed the CT in a single visit in cases without periapical or interradicular radiolucency (PIR) or in multiple visits in cases with PIR. Participants were selected based on specific inclusion and exclusion criteria, and randomly allocated into two groups: Group 1 (G1) - iodoform paste (iodoform + camphorated parachlorophenol + ointment comprising prednisolone acetate $5.0 \mathrm{mg}$ and rifamycin $1.5 \mathrm{mg})$; Group 2 (G2) - Calen ${ }^{\circledast} / \mathrm{ZO}$ paste. Treated teeth were restored with composite resin immediately after the root canal filling. The outcomes were evaluated clinically and radiographically according to specific criteria. Two blinded and standardized evaluators assessed the radiographic outcomes. We used descriptive analyses due to the small sample size. CTs were performed due to caries lesions in $70.4 \%$ of the cases and due to trauma in $29.6 \%$. Only one tooth of G1 was unsuccessful; hence, pulpectomy performance in both groups was not influenced by the filling material, nor by any other analyzed variable. The level of the root canal filling was better in the Calen ${ }^{\circledast} / \mathrm{ZO}$ group. The clinical and radiographic twelve-month outcomes indicated successful treatment, independently of the root filling material used.
\end{abstract}

Keywords: Tooth; Deciduous; Root Canal Obturation; Dental Materials; Clinical Study.

\section{Introduction}

The success of root canal treatment (CT) depends completely on the accurate accomplishment of all operative steps, ${ }^{1}$ including removal of irreversibly inflamed or necrotic radicular pulp tissue, cleaning of the root canal system, and filling with a resorbable filling material. ${ }^{2}$ Furthermore, smear layer removal during the canal chemomechanical preparation is believed to improve pulpectomy outcomes in primary teeth. ${ }^{3}$

Given the complex root canal system of primary molars, the reduction or elimination of bacteria depends not only on the chemomechanical preparation, but also on the filling material, which should possess some 
antimicrobial properties. ${ }^{4}$ In addition, filling materials should be biocompatible with periapical tissues, and should prevent canal reinfection. ${ }^{1}$ The guidelines for primary pulpectomies recommend the use of pure zinc oxide eugenol (ZOE), non-setting calcium hydroxide paste, or calcium hydroxide and iodoform paste. ${ }^{2,5}$

The use of ZOE has decreased as it can delay natural exfoliation. ${ }^{6}$ In addition, the poor resorption ability of $\mathrm{ZOE}^{7}$ and the ectopic eruption of permanent teeth due to this material ${ }^{8}$ are some factors that contribute to the search for alternative materials, such as iodoform and calcium hydroxide-based pastes. ${ }^{9}$ There are many available filling materials for this purpose; however, none of them possesses all the ideally required characteristics and properties. ${ }^{10}$

In the consulted literature, there is no randomized controlled clinical trial, with adequate methodology, conducted to evaluate the performance of root filling materials after smear layer removal in pulpectomy of primary teeth. Therefore, this study aimed to investigate the clinical and radiographic performance of pulpectomies using 1) iodoform paste and 2) calcium hydroxide/zinc oxide $\left(\mathrm{Calen}^{\circledR} / \mathrm{ZO}\right.$ ) paste (thickened by the manufacturer) in primary teeth with irreversible pulpitis or pulp necrosis caused by dental caries or trauma.

\section{Methodology}

\section{Study design}

The present study was designed as a controlled, double blind, randomized clinical trial conducted in Rio de Janeiro, Brazil. The investigation was designed, analyzed, and interpreted according to the Consolidated Standards of Reporting Trials (CONSORT) ${ }^{11,12}$

\section{Participants and recruitment}

This trial was conducted at the Department of Pediatric Dentistry and Orthodontics, School of Dentistry, Universidade Federal do Rio de Janeiro, Rio de Janeiro, RJ, Brazil, from June, 2015 to June, 2017. The Research Ethics Committee approved the study (CAAE: 36760614.0.2001.5257). Participation in the study was voluntary, and the parents/guardians received all information regarding the pulpectomy procedure, such as the advantages and the possible risks or discomfort associated with the required treatment. Informed written consent was obtained.

Participants were healthy patients aged between two and nine years, with one, or at most, two anterior or posterior primary teeth with irreversible pulp inflammation or pulp necrosis caused by dental caries or trauma. Participants were eligible for inclusion if they met the following criteria: a) teeth with deep caries lesions and associated interradicular and/or periapical radiolucencies; b) caries-affected teeth with abnormal mobility due to periapical pathosis, but not associated with normal exfoliation; c) history of spontaneous pain; d) teeth presenting with intra-oral swelling or draining sinus tract; e) continuous bleeding after amputation of coronal pulp tissue; and f) teeth with external physiological or pathological resorption involving less than one third of the root length. ${ }^{3}$

Children were not eligible if they presented with: a) systemic pathosis (medically compromising conditions and special health-care needs); $b$ ) history of allergic reaction to local anesthetics or to the components of the test materials; $\mathrm{c}$ ) antibiotic therapy in the 30 days prior to the intervention or during the $\mathrm{CT}$; d) tooth unable to be restored or impossibility of adequate rubber dam isolation; tooth that had previously been handled; e) interradicular or periapical radiolucency involving more than half of the shortest root measured vertically; f) internal root resorption; g) physiological or pathological external root resorption of more than one third of its length; h) obliteration of the root canal; or i) inadequate bone support evidenced by non-physiological tooth mobility compared with the contralateral tooth. ${ }^{3}$

\section{Sample determination and randomization}

All children who visited the clinic during the recruitment period and met the inclusion criteria without any exclusion criteria were included in this study. Randomization was performed by coin toss by a third person not involved with the clinical assessment or with data analysis, previously to the root canal filling procedure. 


\section{Intervention}

To confirm the need for pulpectomy, a single investigator (D.C.) performed a detailed interview, a clinical examination, and a standard periapical radiographic evaluation with pediatric radiographic films and film-positioning devices. When indicated, a conservative procedure was adopted and the tooth was excluded from the final sample.

For teeth with irreversible pulpitis or necrosis without interradicular or periapical radiolucency, endodontic treatment was performed in a single visit. Multiple sittings were required only in cases of necrosis with interradicular or periapical radiolucency.

Following local anesthesia with $2 \%$ lidocaine and 1:100,000 epinephrine (Alphacaine, DFL, Rio de Janeiro, Brazil) and rubber dam isolation, a diamond bur mounted on a high-speed hand piece was used to create the access to the pulp chamber. Following removal of carious tissue, chemomechanical preparation was carried out using an adapted protocol (Figure 1) for primary teeth pulpectomy with smear layer removal described by Barcelos et al. ${ }^{3}$ For all cases, a single trained operator (D.C.) performed the CT. Root canals were dried with sterile paper points and randomly filled with one of the materials using a lentulo spiral (Maillefer, Balaigues, Switzerland) calibrated at the working length. Teeth assigned to Group 1 received iodoform paste as filling material (iodoform + camphorated parachlorophenol + ointment comprising $5.0 \mathrm{mg}$ prednisolone acetate and $1.5 \mathrm{mg}$ rifamycin); those allocated to Group 2 received Calen ${ }^{\circledast} / \mathrm{ZO}$ paste; S.S.White Artigos Dentários Ltda., Rio de Janeiro, Brazil) as filling material. The entry of the root canal was sealed with heated gutta-percha, and the tooth was restored with composite resin in the same sitting in which the roots were filled. Children and care providers were blinded to the filling material used. Immediately after the completion of treatment, a post-operative standardized periapical radiograph was taken.

In cases where two sittings were required, after the root canals were dried, a cotton pellet slightly moistened with camphorated paramonochlorophenol (Biodinamica, Parana, Brazil) was placed into the pulp chamber and coated with heated gutta-percha.
A temporary restoration was carried out with conventional glass ionomer cement (Riva Self Cure, SDI, Victoria, Australia). One week later, in the absence of any signs and symptoms, using local anesthesia and rubber dam isolation, the root canals were irrigated with $10 \mathrm{~mL}$ of $0.9 \%$ physiologic solution, dried with sterile paper points, and randomly filled as previously described. If any sign or symptom of infection (pain, swelling, fistula or sensitivity to percussion) were still present, chemomechanical preparation would be repeated and a third appointment would be scheduled a week later to complete the treatment. If any signs or symptoms of infection remained, tooth extraction would be planned, and space maintenance would be considered.

\section{Outcomes and analyzed variables}

The outcomes were evaluated clinically at one, three, six, and twelve months post-treatment, and clinically and radiographically at six and twelve months post-treatment. Two blinded and trained evaluators (Kappa $=1.0)$ independently examined the pre-operative and post-treatment radiographs, and this information was added to the patient's dental records with a consensus on the treatment outcome. If there was any disagreement, the lower category was used. The assessors were blind to the material used.

Treatment outcomes (dependent variables) were judged as success or failure according the criteria described by Barcelos et al. ${ }^{3}$ (Figure 2). Clinical success was deemed the absence of signs or symptoms of infection, such as pain, swelling, fistula, or sensitivity to percussion. The radiographic criteria for success included a reduction in the size of the previous radiolucent area, or no new radiolucency. Teeth would be excluded from the study and endodontically retreated if total loss of root canal seal (restorative material and coating of gutta-percha) occured without clinical symptomatology or radiographic alteration.

The primary independent variable analyzed in relation to treatment outcome was root canal filling paste - iodoform (G1) or Calen ${ }^{\circledR} /$ ZO-based (G2). The following variables were also evaluated: a) patient age at the time of therapy; b) region of 
Irreversible pulpitis or Necrosis without inter-radicular or periapical radiolucency

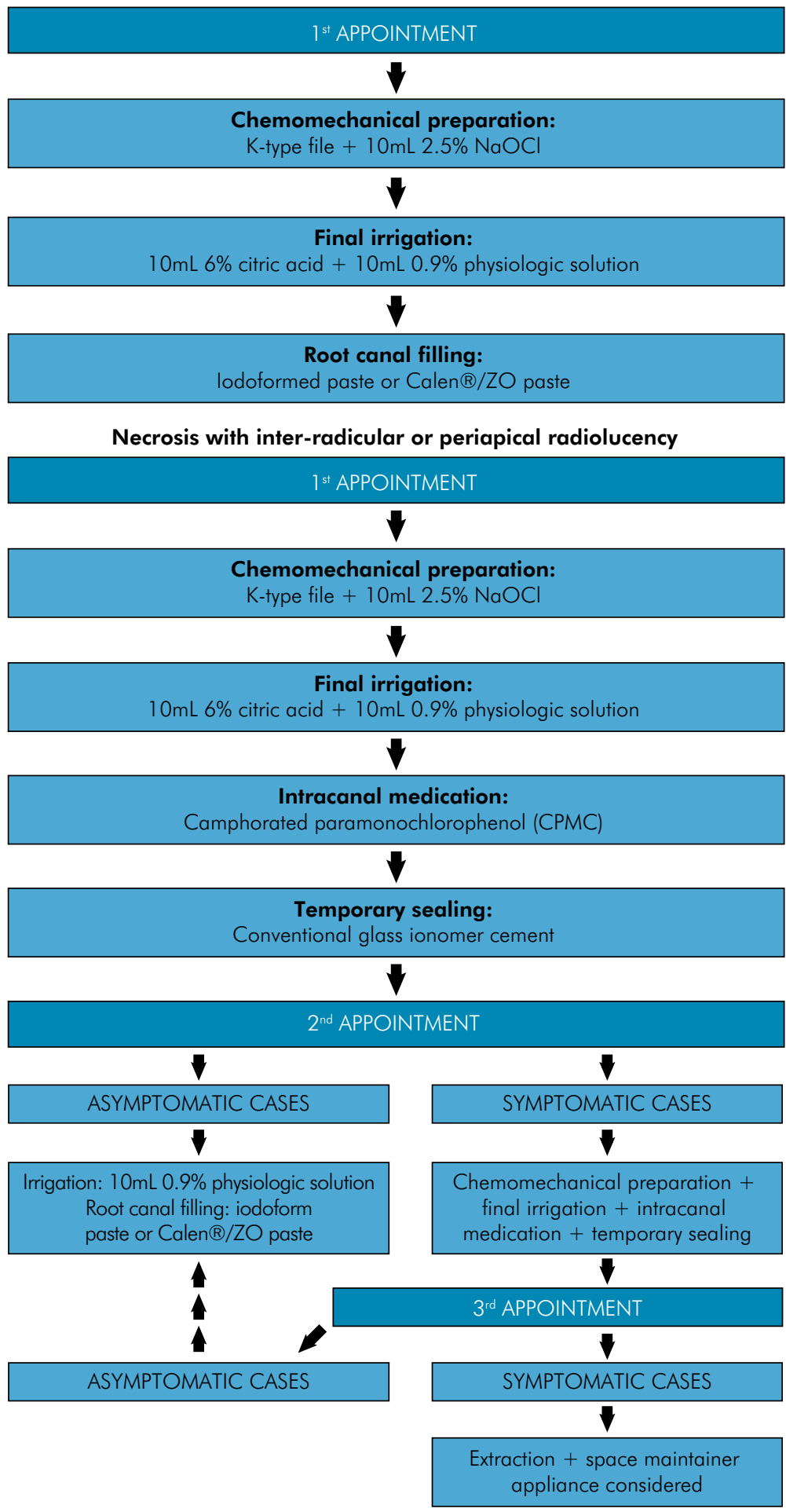

Figure 1. Protocol for pulpectomy in primary teeth with smear layer removal

treated teeth (anterior or posterior); c) arch of treated teeth (maxillary or mandibular); d) initial pulp condition (irreversible pulpitis, necrosis without periapical or interradicular radiolucency, necrosis with periapical or interradicular radiolucency); e) cause of pulp pathology (caries or trauma); 


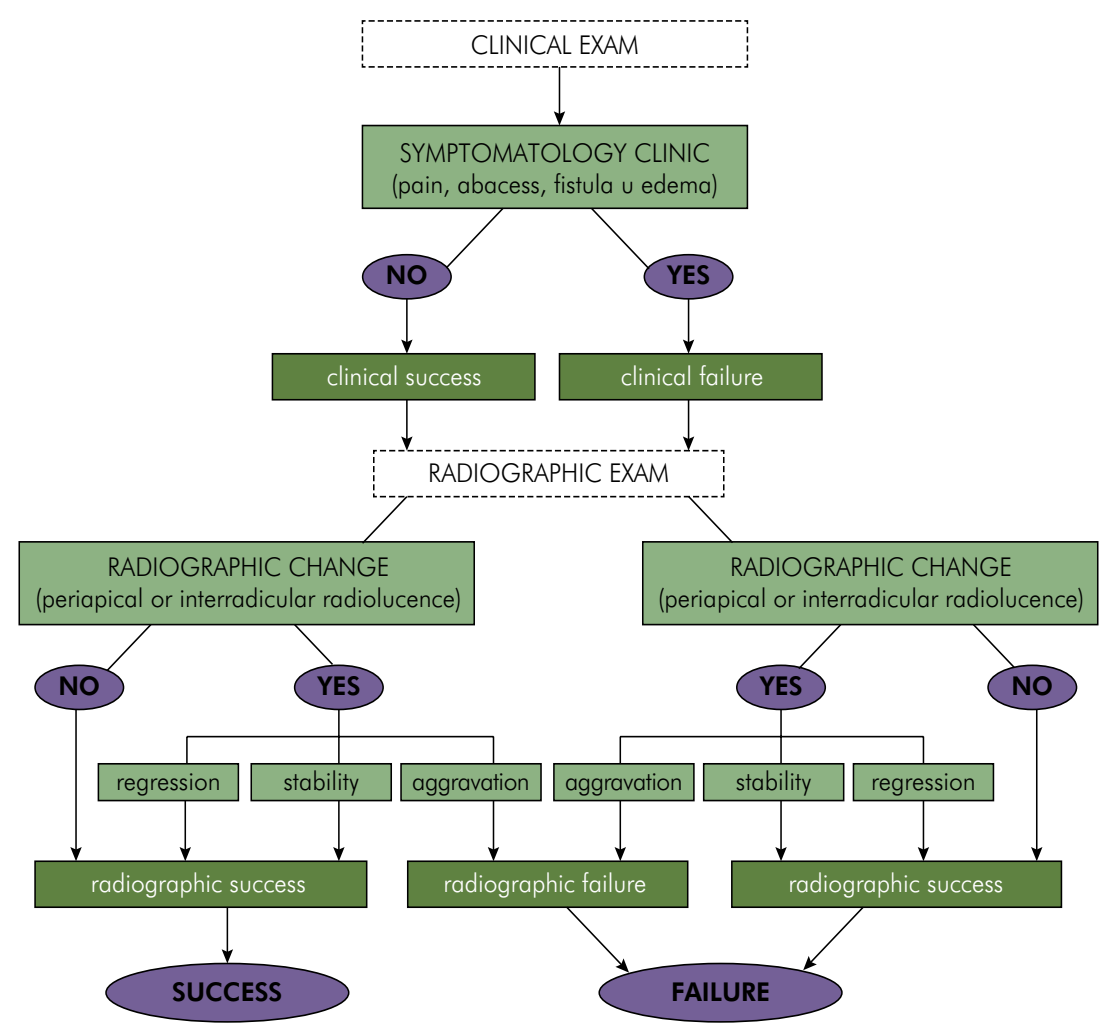

Figure 2. Clinical and radiographic criteria for monitoring pulpectomy.

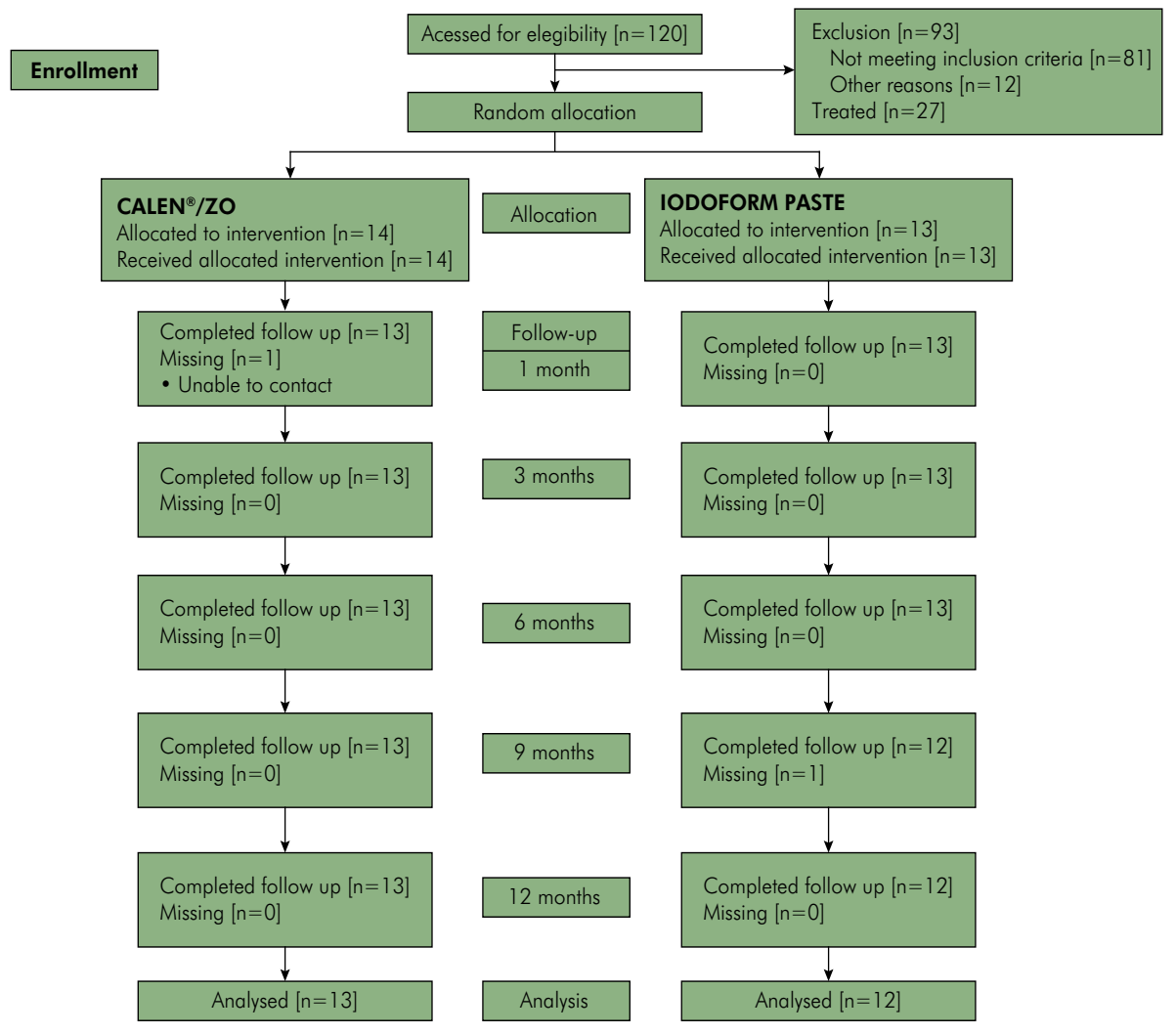

Figure 3. CONSORT flowchart. 
Iodoform Vs Calcium Hydroxide/Zinc Oxide based pastes: 12-month findings of a Randomized Controlled Trial

Table 1. Baseline characteristics of the sample for each group $(n=27)$.

\begin{tabular}{|c|c|c|c|}
\hline \multirow{2}{*}{ Characteristics } & Gl (filled with iodoform paste) & G2 (filled with Calen ${ }^{\circledast} / Z O$ ) & Total \\
\hline & n (\% per group) & n (\% per group) & $\mathrm{G} 1+\mathrm{G} 2$ \\
\hline \multicolumn{4}{|l|}{ Tooth region } \\
\hline Anterior & $10(76.9)$ & $10(71.4)$ & $20(74.1)$ \\
\hline Posterior & $3(23.1)$ & $4(28.6)$ & $7(25.9)$ \\
\hline Total & $13(100)$ & $14(100)$ & $27(100)$ \\
\hline \multicolumn{4}{|l|}{ Tooth arch } \\
\hline Maxillary arch & $12(92.3)$ & $12(85.7)$ & $24(88.9)$ \\
\hline Mandibular arch & $1(7.7)$ & $2(14.3)$ & $3(11.1)$ \\
\hline Total & $13(100)$ & $14(100)$ & $27(100)$ \\
\hline \multicolumn{4}{|l|}{ Cause } \\
\hline Dental caries & $8(61.5)$ & $11(78.6)$ & $19(70.4)$ \\
\hline Trauma & $5(38.5)$ & $3(21.4)$ & $8(29.6)$ \\
\hline Total & $13(100)$ & $14(100)$ & $27(100)$ \\
\hline \multicolumn{4}{|l|}{ Pulpal diagnosis } \\
\hline Irreversible pulpitis & $4(30.8)$ & $7(50.0)$ & $11(40.7)$ \\
\hline Pulp necrosis without periapical radiolucency & $3(23.0)$ & $3(21.4)$ & $6(22.3)$ \\
\hline Pulp necrosis with periapical radiolucency & $6(46.2)$ & $4(28.6)$ & $10(37.0)$ \\
\hline Total & $13(100)$ & $14(100)$ & $27(100)$ \\
\hline \multicolumn{4}{|l|}{ Clinical signs or symptoms } \\
\hline Absent & $7(53.8)$ & $4(28.6)$ & 11 (40.7) \\
\hline Present & $6(46.2)$ & $10(71.4)$ & $16(59.3)$ \\
\hline Total & $13(100)$ & $14(100)$ & $27(100)$ \\
\hline
\end{tabular}

f) pre-operative clinical signs and symptoms (present or absent); g) pre-operative periapical or interradicular radiolucency (present or absent); h) level of root canal filling; and (i) integrity of crown restoration at follow-up visits. Level of the root canal filling was documented from the immediate post-treatment radiograph as under-filled (when the filling paste ended $1 \mathrm{~mm}$ or more short of the apex), flush-filled (when the filling paste appeared to end at the radiographic apex), or overfilled (when the filling paste extruded past the radiographic apex). Results were recorded and analyzed using the statistical package SPSS v. 21.0 (SPSS Inc, Chicago, IL, USA). We used descriptive analyses due to the small sample size.

\section{Results}

The trial included 39 teeth in 35 children; however, a conservative procedure was performed on 12 teeth. The pulpectomy procedure was performed on 27 teeth of 23 children ( $69.6 \%$ boys and $30.4 \%$ girls). The mean age of the patients was $3.68 \pm 1.67$ years. The present study is summarized in a CONSORT flowchart (Figure 3). Description of the teeth in each group regarding the jaw, tooth type, cause of pulp pathology, pulp diagnosis, radiographic signs and the clinical signs and symptoms is shown in Table 1. In 19 teeth (70.4\%), the CT was performed due to caries lesions and in eight teeth $(29.6 \%)$, due to trauma. 
Table 2. Clinical, radiographical, and overall pulpectomy outcome at 6,9, and 12 months compared by groups.

\begin{tabular}{|c|c|c|c|c|}
\hline \multirow{3}{*}{ Pulpectomy outcome } & \multicolumn{2}{|c|}{ G1 (lodoform paste $n=13$ ) } & \multicolumn{2}{|c|}{ G2 $\left(\right.$ Calen ${ }^{\circledR} /$ ZO paste $\left.n=14\right)$} \\
\hline & Success & Failure & Success & Failure \\
\hline & n (\%) & n (\%) & n (\%) & n (\%) \\
\hline \multicolumn{5}{|c|}{6 months (missing $=1[G 2]$ ) } \\
\hline Clinical & $13(100.0)$ & $0(0.0)$ & $13(100.0)$ & $0(0.0)$ \\
\hline Radiographical & $13(100.0)$ & $0(0.0)$ & $13(100.0)$ & $0(0.0)$ \\
\hline Overall & $13(100.0)$ & $0(0.0)$ & $13(100.0)$ & $0(0.0)$ \\
\hline \multicolumn{5}{|c|}{9 months (missing = $1[G 1])$} \\
\hline Clinical & $12(100.0)$ & $0(0.0)$ & $13(100.0)$ & $0(0.0)$ \\
\hline Radiographical & $12(100.0)$ & $0(0.0)$ & $13(100.0)$ & $0(0.0)$ \\
\hline Overall & $12(100.0)$ & $0(0.0)$ & $13(100.0)$ & $0(0.0)$ \\
\hline \multicolumn{5}{|l|}{12 months } \\
\hline Clinical & $12(100.0)$ & $0(0.0)$ & $13(100.0)$ & $0(0.0)$ \\
\hline Radiographical & $11(91.7)$ & $1(8.3)$ & $13(100.0)$ & $0(0.0)$ \\
\hline Overall & $11(91.7)$ & $1(8.3)$ & $13(100.0)$ & $0(0.0)$ \\
\hline
\end{tabular}

Table 3. Level of the root filling material for each group.

\begin{tabular}{lccc}
\hline \multirow{2}{*}{ Extension } & G1 & \multicolumn{1}{c}{ G2 } & \\
\cline { 2 - 3 } & $\begin{array}{c}\text { (filled with } \\
\text { iodoform paste) }\end{array}$ & $\begin{array}{c}\text { (filled with } \\
\left.\text { Calen }{ }^{\circledR} / \mathrm{ZO}\right)\end{array}$ & \multirow{2}{*}{ Total } \\
\cline { 2 - 3 } & $\mathrm{n}$ (\% per group) & $\mathrm{n}$ (\% per group) & \\
\hline Under-filled & $5(83.3)$ & $1(16.7)$ & $6(100)$ \\
Flush-filled & $4(30.8)$ & $9(69.2)$ & $13(100)$ \\
Overfilled & $4(50.0)$ & $4(50.0)$ & $8(100)$ \\
\hline
\end{tabular}

Two teeth were excluded from the analysis: one (G2) because the patient did not attend any follow-up visits and one (G1) because it was mistakenly treated by a dental student, after the six-month assessment. The remaining 25 teeth complete the follow-up period. At six- and nine-month evaluation, no failure was found. At 12 months, no clinical failure as recorded although a radiographic failure was counted for G1, yielding an overall success rate of $97.1 \%$ and $100.0 \%$ for G1 and G2, respectively (Table 2). The distribution of overall pulpectomy (dependent variable) compared by group (primary independent variable) and some secondary independent variables (cause of tooth pathology, clinical or radiographic previous signs and symptoms, pulp condition, and the level of root canal obturation) are presented in Table 3. No measure of association was computed for the cross tabulation of any independent variables versus the dependent variable, as there was one tooth classified as failure. No tooth had total loss of root canal seal.

\section{Discussion}

We attributed the high success rate in this study to several factors. First, besides performing an effective reduction of bacterial load in the cases of infection or necrosis and the maintenance of asepsis in cases of vital pulps, ${ }^{2}$ we used two root filling materials that have shown positive properties in several studies. ${ }^{13,14,15}$ Second, smear layer removal was performed on all treated teeth. Third, we ensured a good crown seal in the same visit in which the root canals were filled. Finally, treatment was performed by a highly skilled operator. Other factors that might have influenced our results are stringent case selection, as this can play an important role in the outcome of pulpectomies, ${ }^{16}$ as well as the strict follow-up of patients during the post-operative period. Rigorous selection criteria and the high technical skill of the operator in a clinical trial usually leads to higher prevalence of success. However, this may not reflect usual clinical practice. ${ }^{17}$ 
All treatments were performed with smear layer removal in association with the chemomechanical preparation, as this has been shown to improve the pulpectomy outcome in primary teeth ${ }^{3,7}$. This step increases dentine permeability, promoting better adaptation of the filling materials and improves disinfection and sealing of root canals. ${ }^{18}$ Although a recent systematic review was inconclusive regarding the most effective intra-canal irrigant for smear layer removal, ${ }^{19}$ we chose $6 \%$ citric acid as it has been shown to have the best efficacy without damaging the normal dentinal structures. ${ }^{18}$ In addition, it has been shown to have antibacterial effects in infected root canals,$^{20}$ less toxicity then other solutions such as ethylenediaminetetraacetic acid (EDTA) ${ }^{21}$ and to be quite effective in primary teeth in a short period of time. ${ }^{22}$ For all teeth, we performed the last irrigation with saline solution because washing out the citric acid from the root canal system is indicated for safe endodontic clinical practice. ${ }^{23}$

Sealing of the root canal system is an essential step in successful endodontic treatments as it avoids the penetration of microorganisms and their toxins, helps periapical repair, and prevents reinfection. ${ }^{24}$ It has been confirmed that an optimal filling level directly influences the successful outcome of a CT. ${ }^{25}$ In contrast, in our study, the extent of the root canal filling material did not influence success rate, in agreement with previous study. As the high frequency of ideal level of the root canal filling was in the Calen ${ }^{\circledast} / \mathrm{ZO}$ group, we believe that the slight thickening of the paste improved its consistency and favored its insertion, facilitating this important step of the treatment. Moreover, an important condition for $\mathrm{CT}$ success is the protection of the filling material with a well-sealed crown restoration, ${ }^{1}$ which aims to prevent microleakage. ${ }^{5}$ This can be accomplished by placing a permanent restoration as soon as possible after the completion of the treatment, ${ }^{26}$ delay in the placement of final restorations may result in contamination of the filled root canals. ${ }^{27}$ Considering this, we restored the teeth in the same visit in which the roots were filled.

There is some evidence that suggests that single and multiple visits present similar clinical and radiographic success. ${ }^{28,29,30}$ In this sense, the two-visit protocol used only for the necrotic pulp conditions ${ }^{3}$ with periapial radiolucence might probably have not impaired the results. Multiple visits should be viewed as an endodontic therapy option, since the circumstances of each case should be carefully considered. ${ }^{28}$ Nevertheless, the American Academy of Pediatric Dentistry Guideline does not have a specific recommendation for single-visit or multiplevisit protocols for the pulpectomy procedure in primary teeth. ${ }^{5}$

In this study, only one failure occurred, limiting the accomplishment of statistical inferences about the possible variables related to treatment outcome. However, it occurred in a tooth with a previous periapical alteration due to caries lesion and that presented loss of coronary restoration. These factors had already been related to endodontic treatment failure. RCT seems to have a higher success rate when performed in symptomless teeth with no or minimal root resorption and/or periapical infection. ${ }^{31}$ Breakdown, fracture or loss of the temporary/ permanent restoration can also contribute to the failure of endodontic treatment. ${ }^{27}$ Therefore, we can infer that a successful CT can be achieved regardless of such factors if great attention is given to the selection and follow-up of the cases, the chemomechanical preparation of the root canal system, the smear layer removal, and the coronal sealing; all filled root canals had their entries protected with gutta-percha. In addition, fractured or lost restorations were immediately replaced, because children's guardians were in close contact with the operator.

Iodoform pastes have excellent antibacterial and anti-inflammatory properties, as well as good radiopacity and easy resorption when extruded to periapical tissues. ${ }^{13}$ However, iodoform-based products can lead to discoloration of the dental crown, ${ }^{32}$ which may limit their use in anterior teeth. Calcium hydroxide pastes do not cause such impairment and are widely used, mainly due to their low toxicity and antibacterial, antifungal, and biocompatibility properties. ${ }^{14}$ On the other hand, they have rapid resorption and low radiopacity, which can be improved by the addition of zinc oxide to their composition. ${ }^{33}$ Therefore, we believe 
that newer preparations of filling materials, such as the Calen ${ }^{\circledast} / \mathrm{ZO}$ paste, are interesting.

Despite the small sample size, we believe that the rigorous selection criteria minimized bias in our study. Another limitation of the study is the clustering of teeth within individuals, considering that a single patient could have more than one tooth treated. No attempt was made to account for clustering as the results were presented solely in a descriptive form and no inferential statistics was applied. This trial aimed to conduct an initial exploratory analysis, considering that an unsuccessful root canal treatment usually shows clinical or radiographic signs of failure during the first six months ${ }^{34}$. However, more trials should be performed with multiple operators, a larger sample size, and longer follow-ups to verify the clinical and radiographic long-term success

\section{References}

1. Silva LA, Leonardo MR, Oliveira DS, Silva RA,

Queiroz AM, Hernández PG et al. Histopathological

evaluation of root canal filling materials for

primary teeth. Braz Dent J. 2010 Jan;21(1):38-45.

https://doi.org/10.1590/S0103-64402010000100006

2. Rodd HD, Waterhouse PJ, Fuks AB, Fayle SA, Moffat MA. Pulp therapy for primary molars.. Int J Paediatr Dent. 2006;16(1 Suppl):15-23. https://doi.org/10.1111/j.1365-263X.2006.00774.x

3. Barcelos R, Tannure PN, Gleiser R, Luiz RR, Primo LG. The influence of smear layer removal on primary tooth pulpectomy outcome: a 24-month, double-blind, randomized, and controlled clinical trial evaluation. Int J Paediatr Dent. 2012 Sep;22(5):369-81. https://doi.org/10.1111/j.1365-263X.2011.01210.x

4. Piva F, Faraco Junior IM, Estrela C. Antimicrobial activity of different root canal filling pastes used in deciduous teeth. Mater Res. 2008;11(2):171-3. https://doi.org/10.1590/S1516-14392008000200010

5. American Academy of Pediatric Dentistry. Guideline on pulp therapy for primary and young permanent teeth. Pediatr Dent. 2017-2018;39:325-33

6. Dunston B, Coll JA. A survey of primary tooth pulp therapy as taught in US dental schools and practiced by diplomates of the American Board of Pediatric Dentistry. Pediatr Dent. 2008 Jan-Feb;30(1):42-8.

7. Tannure PN, Azevedo CP, Barcelos R, Gleiser R, Primo LG. Long-term outcomes of primary tooth pulpectomy with and without smear layer removal: a randomized split-mouth clinical trial. Pediatr Dent. 2011 Jul-Aug;33(4):316-20. rates, and follow the development of the successor permanent teeth.

\section{Conclusion}

The clinical and radiographic twelve-month outcomes indicated successful treatment, independently of the root filling material used, iodoform based paste or Calen ${ }^{\circledast} / \mathrm{ZO}$, although the frequency of ideal level of the root canal filling was higher in Calen ${ }^{\circledR} / \mathrm{ZO}$ group.

\section{Acknowledgments}

The authors wish to thank S.S.White Artigos Dentários Ltda., Rio de Janeiro, Brazil, for providing the Calen ${ }^{\circledast} / Z O$ paste for this study, and FAPERJ and CAPES for financial support.

8. Tannure PN, Fidalgo TK, Barcelos R, Gleiser R, Primo LG. Ectopic eruption of permanent incisors after predecessor pulpectomy: five cases. Gen Dent. 2011 Jul-Aug;59(4):e162-7.

9. Mortazavi M, Mesbahi M. Comparison of zinc oxide and eugenol, and Vitapex for root canal treatment of necrotic primary teeth. Int J Paediatr Dent. 2004 Nov; 14(6):417-24. https://doi.org/10.1111/j.1365-263X.2004.00544.x

10. Pinto DN, de Sousa DL, Araújo RB, Moreira-Neto JJ. Eighteen-month clinical and radiographic evaluation of two root canal-filling materials in primary teeth with pulp necrosis secondary to trauma. Dent Traumatol. 2011 Jun;27(3):221-4. https://doi.org/10.1111/j.1600-9657.2011.00978.x

11. Altman DG, Schulz KF, Moher D, Egger M, Davidoff $F$, Elbourne D, et al.The revised CONSORT statement for reporting randomized trials: explanation and elaboration. Ann Intern Med. 2001 Apr;134(8):663-94. https://doi.org/10.7326/0003-4819-134-8-200104170-00012

12. Moher D, Jones A, Lepage L. Use of the CONSORT statement and quality of reports of randomized trials: a comparative before-and-after evaluation. JAMA. 2001 Apr;285(15):19925. https://doi.org/10.1001/jama.285.15.1992

13. Cerqueira DF, Mello-Moura AC, Santos EM, Guedes-Pinto AC. Cytotoxicity, histopathological, microbiological and clinical aspects of an endodontic iodoform-based paste used in pediatric dentistry: a review. J Clin Pediatr Dent. 2008;32(2):105-10. https://doi.org/10.17796/icpd.32.2.klwx5571h2w85430 
14. Desai S, Chandler N. Calcium hydroxide-based root canal sealers: a review. J Endod. 2009 Apr;35(4):475-80. https://doi.org/10.1016/j.joen.2008.11.026

15. Barja-Fidalgo F, Moutinho-Ribeiro M, Oliveira MA, Oliveira $\mathrm{BH}$. A systematic review of root canal filling materials for deciduous teeth: is there an alternative for zinc oxide-eugenol? ISRN Dent. 2011;2011:367318. https://doi.org/10.5402/2011/367318

16. Pramila R, Muthu MS, Deepa G, Farzan JM, Rodrigues SJ. Pulpectomies in primary mandibular molars: a comparison of outcomes using three root filling materials. Int Endod J. 2016 May;49(5):413-21. https://doi.org/10.1111/iej.12478

17. Smaïl-Faugeron V, Courson F, Durieux P, Muller-Bolla M, Glenny AM, Fron Chabovis H. Pulp treatment for extensive decay in primary teeth. Cochrane Database Syst Rev. 2014 Aug;6(8):CD003220. https://doi.org/10.1002/14651858.CD003220.pub2

18. Hariharan VS, Nandlal B, Srilatha KT. Efficacy of various root canal irrigants on removal of smear layer in the primary root canals after hand instrumentation: a scanning electron microscopy study. J Indian Soc Pedod Prev Dent. 2010 Oct-Dec;28(4):271-7. https://doi.org/10.4103/0970-4388.76157

19. Pozos-Guillen A, Garcia-Flores A, Esparza-Villalpando V, Garrocho-Rangel A. Intracanal irrigants for pulpectomy in primary teeth: a systematic review and meta-analysis. Int J Paediatr Dent. 2016 Nov;26(6):412-25. https://doi.org/10.1111/ipd.12228

20. Yamaguchi M, Yoshida K, Suzuki R, Nakamura H. Root canal irrigation with citric acid solution. J Endod. 1996 Jan;22(1):27-9. https://doi.org/10.1016/S0099-2399(96)80232-9

21. Amaral KF, Rogero MM, Fock RA, Borelli P, Gavini G. Cytotoxicity analysis of EDTA and citric acid applied on murine resident macrophages culture. Int Endod J. 2007 May;40(5):338-43. https://doi.org/10.1111/j.1365-2591.2007.01220.x

22. Salama FS, Abdelmegid FY. Six percent citric acid better than hydrogen peroxide in removing smear layer: an in vitro pilot study. Pediatr Dent. 1994 Nov-Dec;16(6):424-6.

23. Guimarães LF, Fidalgo TK, Menezes GC, Primo LG, Costa e Silva-Filho F. Effects of citric acid on cultured human osteoblastic cells. Oral Surg Oral Med Oral Pathol Oral Radiol Endod. 2010 Nov;110(5):665-9. https://doi.org/10.1016/i.tripleo.2010.07.003
24. Estrela C, Holland R, Estrela CR, Alencar AH, Sousa-Neto MD, Pécora JD. Characterization of successful root canal treatment. Braz Dent J. 2014 Jan-Feb;25(1):3-11. https://doi.org/10.1590/0103-6440201302356

25. Barcelos R, Santos MP, Primo LG, Luiz RR, Maia LC. ZOE paste pulpectomies outcome in primary teeth: a systematic review. J Clin Pediatr Dent. 2011;35(3):241-8. https://doi.org/10.17796/jcpd.35.3.y777187463255n34

26. Moskovitz M, Sammara E, Holan G. Success rate of root canal treatment in primary molars. J Dent. 2005 Jan;33(1):41-7. https://doi.org/10.1016/i.jdent.2004.07.009

27. Siqueira JF Jr, Rôças IN, Lopes HP, de Uzeda M. Coronal leakage of two root canal sealers containing calcium hydroxide after exposure to human saliva. J Endod. 1999 Jan;25(1):14-6. https://doi.org/10.1016/S0099-2399(99)80391-4

28. Singla R, Marwah N, Dutta S. Single Visit versus Multiple Visit Root Canal Therapy. Int J Clin Pediatr Dent. 2008 Sep;1(1):17-24. https://doi.org/10.5005/ip-journals-10005-1004

29. Bharuka SB, Mandroli PS. Single- versus two-visit pulpectomy treatment in primary teeth with apical periodontitis: A double-blind, parallel group, randomized controlled trial. J Indian Soc Pedod Prev Dent. 2016 Oct-Dec;34(4):383-90. https://doi.org/10.4103/0970-4388.191429

30. Sevekar SA, Gowda SH. Postoperative Pain and Flare-Ups: Comparison of Incidence Between Single and Multiple Visit Pulpectomy in Primary Molars. J Clin Diagn Res. 2017 Mar;11(3):ZC09-12. https://doi.org/10.7860/JCDR/2017/22662.9377

31. Holan G. Long-term effect of different treatment modalities for traumatized primary incisors presenting dark coronal discoloration with no other signs of injury. Dent Traumatol. 2006 Feb;22(1):14-7. https://doi.org/10.1111/j.1600-9657.2006.00346.x

32. Priyanka C, Govardhan P. Tooth discolouration due to endodontic materials and procedures. IOSR-JDMS. 2013;9(4):32-6. https://doi.org/10.9790/0661-1263235

33. Queiroz AM, Assed S, Consolaro A, Nelson-Filho $P$, Leonardo MR, Silva RA et al. Subcutaneous connective tissue response to primary root canal filling materials. Braz Dent J. 2011;22(3):203-11. https://doi.org/10.1590/S0103-64402011000300005

34. Ozalp N, Saroğlu I, Sönmez H. Evaluation of various root canal filling materials in primary molar pulpectomies: an in vivo study. Am J Dent. 2005 Dec;18(6):347-50. 